\title{
Internet use and aggression in adolescents with attention deficit hyperactivity disorder
}

\author{
Sevim Berrin Inci Izmir ${ }^{1}$, Melis Ipci $^{2}$, Eyup Sabri Ercan ${ }^{3}$ \\ 'Ege University, Department of Toxicology and Drug Addiction Sciences, Izmir - Turkey \\ ${ }^{2}$ Hasan Kalyoncu University Institute of Social Sciences, Department of Clinical Psychology, Gaziantep - Turkey \\ ${ }^{3}$ Ege University, Department of Child and Adolescent Psychiatry, Izmir - Turkey
}

\begin{abstract}
Objective: The aim of this study was to investigate the relationship between internet addiction and aggression in adolescents with Attention Deficit Hyperactivity Disorder (ADHD). In addition, we aimed to explore the differences between ADHD subtypes (inattentive type; combination type; hyperactive-impulsive type).

Method: The sample consisted of a total of 120 adolescents. The study group included 60 individuals aged between 13 and 17 years (14.70 \pm 2.07$)$ who had presented to a child and adolescent psychiatry clinic and received a diagnosis of ADHD according to the DSM-IV after being interviewed by a specialist, while 60 adolescents without a diagnosis of ADHD made up the control group. Kiddie-Schedule for Affective Disorders and Schizophrenia, present and life time version (K-SADS-PL), Buss-Perry Aggression Questionnaire (BPAQ), Internet Addiction Diagnostic Questionnaire (IADQ), and a semi structured sociodemographic form were used as measurement devices.

Results: According to the results of statistical analyses, the ratio of internet addiction and aggression were higher in adolescents with ADHD than in the control group. Especially the rate of internet addiction and aggression was higher in adolescents with ADHD combination type. In addition, there is a positive relationship between internet addiction and aggression in adolescents with ADHD.

Conclusion: According to our study results, there is a positive relationship between internet addiction and aggression in adolescents with ADHD. The results of our study will be helpful to develop future protective measures in internet addiction aimed at preventing aggressive behavior of adolescents with ADHD.
\end{abstract}

Keywords: ADHD, aggression, adolescents, internet addiction

\section{INTRODUCTION}

In our days, the internet has become a commonly used tool of communication, not least as a means for speeding up access to information and communication. Alongside the convenience that the internet offers, it is also thought to affect people's daily lives in ways that may be called problematic, leading to procrastination or having negative effects on everyday activities (1). Problematic internet use may be defined by inappropriate and dysfunctional obsession with internet use and related excessive and uncontrolled desires and impulses, and problematic internet use can cause internet addiction (2). First proposed in the academic world by Young, the concept of internet addiction includes signs such as an excessive

How to cite this article: Inci Izmir SB, Ipci M, Ercan ES. Internet use and aggression in adolescents with attention deficit hyperactivity disorder. Dusunen Adam The Journal of Psychiatry and Neurological Sciences 2019;32:185-193.

Correspondence: Sevim Berrin Inci Izmir, Ege University, Department of Toxicology and Drug Addiction Sciences, Izmir - Turkey

Phone: +90 2324632721 E-mail: inciberrin@gmail.com

Received: November 02, 2018; Revised: March 01, 2019; Accepted: July 04, 2019 
occupation with the internet, a felt need to use the internet, repeated attempts to stop the use of the internet, a loss of relevance of the time spent away from the internet, spending more time than planned on the internet, and feeling uneasy when being off the internet, which may result in social problems (3). The term "Internet gaming disorder," listed in the latest DSM-5 under the rubric of "requiring further research," has also entered the literature (2). Internet addiction can lead to other psychiatric disorders, alcohol and substance addiction, bodily diseases, and even legal problems (4). Studies carried out in Asia found prevalence rates for Internet addiction among adolescents between 2.4 and $37.9 \%$, while research in Europe showed rates between 3.1 and $18.3 \%$ (5). A study performed in 7 provinces of Turkey with a sample of 14-20 year old youths found an Internet addiction rate of $10.1 \%$ (6). Another study in Turkey undertaken with high school students established a prevalence of Internet and computer addiction of $4.5 \%$ (7). Tsitsika et al. (8) reported that more than half of adolescents with Internet addiction showed comorbidity with another psychiatric disorder. Internet addiction particularly in young persons is frequently seen together with other psychiatric conditions such as attention deficit hyperactivity disorder (ADHD), depression, social anxiety disorder, pathological addiction to gambling, and substance use disorder (9-11). A significant number of studies has shown a correlation between Internet addiction and ADHD in adolescents $(11,12)$.

ADHD is a disorder most frequently seen in childhood that can cause highly relevant academic, social, and psychiatric problems with lifelong negative effects (12). As it affects the health of individuals, their families, and even society, ADHD is considered a significant public health issue. With an onset early in life, ADHD also has a big effect on the individual's socialization (13). Especially in adolescents, deficits in social problem-solving capacities may result in aggression and behavioral disorders (14). After developing Internet addiction, hostile and aggressive attitudes already present in adolescents may, in a vicious circle, lead to an increase of problems like reduced activity, avolition, deterioration of social relations, further reduction of face-to-face contact, and feeling safe only in relations in an Internet environment (15). Previous studies reported that aggression, anger, and emotional outbursts were seen more frequently in children and adolescents with ADHD (16). Yen et al. (17) determined that aggressive behavior is highly correlated with Internet addiction. Similarly, Ko et al.
(18) established a high-level relation between Internet addiction and aggression.

While aggression and ADHD especially in the adolescent age group have been researched extensively, the relation between aggression and ADHD has not been clarified to a satisfactory degree. Particularly in the last few years, aggression has been studied as a multifaceted rather than a single concept, and Internet use was found to be a risk factor for children and adolescents with a diagnosis of ADHD; these developments underline the need for comprehensive assessment of the correlation between Internet addiction, aggression, and ADHD. Aim of our study was to examine the relation between Internet use and aggression in adolescents diagnosed with ADHD. Another aim was to find out if Internet use and aggression are differentiated between the subtypes of ADHD (inattentive, hyperactive-impulsive, and combination type).

\section{METHOD}

\section{Sample}

Our study population consisted of adolescents aged 13-17 years presenting to a private child and adolescent psychiatry clinic in the province of Izmir. Our sample of 120 individuals included 60 adolescents aged 13-17 years $(14.70 \pm 2.07)$ presenting to a private child and adolescent psychiatry clinic, diagnosed by a specialist according to DSM-IV criteria as having ADHD, and 60 adolescents without any psychiatric disorder, including ADHD. Adolescents and their families were informed about the study, and a verbal consent form was received from those volunteering to participate. Not included were children with an age below 13 or above 17 years on the day of the research, those with any comorbidity alongside ADHD, with a psychiatric disorder due to organic causes, specific learning disability or a level of mental retardation hindering the interview. Inclusion criterion for the control group was not receiving any psychiatric diagnosis, ADHD or otherwise. Ethics approval was received from the ethics committee of Hasan Kalyoncu University.

\section{Data collection instruments}

Sociodemographic data form: The study used a 4-point Likert-type personal data form including 14 items developed by the researchers to evaluate participants' age, sex, family education level, environment of Internet use, preferred device to access the Internet, time spent on the Internet, purpose of 
Internet use, and status of problems experienced with their family due to Internet use.

Kiddie-Schedule for Affective Disorders and Schizophrenia, present and life-time version (K-SADS-PL): The K-SADS-PL is a semi-structured interview form developed by Kaufman et al. to detect past and present psychopathologies in children and adolescents according to DSM-III-R and DSM-IV diagnostic criteria (19). The instrument was adapted to Turkish and its validity and reliability studied by Gokler et al. (20). Test-retest reliability examined for 4 main diagnostic groups (anxiety disorders, ADHD, elimination disorders, and tic disorders) at an interval of 4 weeks ranged between 0.62 and 0.87 . For ADHD $(\mathrm{n}=8)$, a reliability of 0.69 was established.

Internet Addiction Diagnostic Questionnaire (IADQ): A self-report instrument to determine Internet addiction developed on the basis of the DSM-IV-TR criteria for pathological gambling, rated on a 6-point Likert-type scale (0: "does not apply" to 5: "always") (21). In the original version of the form, threshold scores to determine addiction were 20-39 points for the category "regular Internet user," 40-69 points "Internet user frequently experiencing problems," and 70-100 points "Internet user experiencing serious problems." However, the version of the scale published at the Internet address www.netaddiction.com uses the following thresholds: 20-49 points "regular Internet user," 50-79 points "Internet user with occasional or frequent problems," and 80-100 points for "Internet user experiencing serious problems." The instrument was adapted to Turkish by Bayraktar, with Cronbach's alpha internal consistency coefficient of 0.91 and a SpearmanBrown value of 0.87 , and in our study, we have accepted the thresholds established by Bayraktar (22) in the Turkish adaptation.

Buss-Perry Aggression Questionnaire (BPAQ): The "Aggression Questionnaire" updated by Buss and Warren (23) includes 34 items scored on a 5-point Likert-type scale. The highest possible score is 170 , the lowest 34 points. A score of 58 and below indicates low aggression, 59-110 a normal level, and a score above 110 a high aggression level. The instrument was adapted to Turkish by Can (24). It aims to measure 4 different dimensions of aggression: physical aggression, verbal aggression, hostility, and anger. The subscale for physical aggression contains 9 questions regarding physical harm caused to others; the subscale for verbal aggression consists of 5 questions about offending others verbally; the anger subscale includes 7 questions measuring the emotional dimension of aggression; and the hostility subscale comprises 8 questions aimed at measuring the cognitive dimension of aggression.

\section{Procedure}

The study included 60 cases of 13- to 17-year-old patients who had presented to a private child and adolescent psychiatry clinic and been diagnosed by a psychiatrist using K-SADS-PL according to DSM-IV diagnostic criteria as having ADHD (criteria: presently meeting 6 out of 9 symptoms for attention deficit or hyperactivity) and 60 individuals without ADHD or any other psychiatric disorder according to DSM-IV diagnostic criteria. The participants were divided into 2 groups: those diagnosed with ADHD formed the study group, those without any psychiatric disorder the control group. After the assessment, both groups were asked to complete the IADQ, a semi-structured sociodemographic form prepared for the study, and the BPAQ.

\section{Statistical analysis}

Before beginning data analysis, accuracy of the data and normal distribution of the variables were tested. In the analyses performed with SPSS version. 18, t-test (independent sample t-test) was carried out, chi-square values and one-way analysis of variance (one-way ANOVA), correlation and regression were used. A p value $<0.05$ was accepted as statistically significant.

\section{RESULTS}

The average age of the patients participating in the study was $14.70 \pm 2.07$ years. Regarding their sociodemographic variables, no significant difference was found between study group and control group ( $\mathrm{p}>0.05)$ (Table 1$)$.

In the study group, average age when starting therapy was $9 \pm 1.47$ years. In order to examine if there were differences according to the age at the beginning of therapy and scores on the IADQ and the BPAQ in the study group, chi-square tests were carried out, finding no significant differences for either IADQ $(\mathrm{p}=0.635)$ or BPAQ $(\mathrm{p}=0.119)$, hence $\mathrm{p}>0.05$ for both instruments. However, in cases beginning therapy at age 7 , scores on the IADQ and on the BPAQ were found to be lower than in cases that had started therapy later $\left(\chi^{2}=9.78, \mathrm{p}>0.05\right)$.

Statistically significant differences in IADQ scores between adolescents in the control group and in the ADHD group were detected by t-test $(p<0.001)$. Frequency distribution analysis found that $20.8 \%$ of the adolescents in the study group had inattentive-type 


\begin{tabular}{|c|c|c|c|c|c|c|c|c|}
\hline & \multicolumn{2}{|c|}{$\begin{array}{c}\text { Study group } \\
n=60\end{array}$} & \multicolumn{2}{|c|}{$\begin{array}{c}\text { Control group } \\
n=60\end{array}$} & \multicolumn{2}{|c|}{$\begin{array}{c}\text { All participants } \\
n=120\end{array}$} & \multirow[b]{2}{*}{ df } & \multirow[b]{2}{*}{$\mathbf{p}$} \\
\hline & Mean & SD & Mean & SD & Mean & SD & & \\
\hline Age & 15.10 & 1.86 & 14.31 & 2.23 & 14.70 & 2.07 & 7 & 0.574 \\
\hline \multicolumn{9}{|l|}{ Socio-economic level } \\
\hline High & \multicolumn{2}{|c|}{$21(28.0 \%)$} & \multicolumn{2}{|c|}{$26(34.7 \%)$} & \multicolumn{2}{|c|}{$47(31.3 \%)$} & & \\
\hline Intermediate & \multicolumn{2}{|c|}{$47(62.7 \%)$} & \multicolumn{2}{|c|}{$35(46.7 \%)$} & \multicolumn{2}{|c|}{$82(54.7 \%)$} & 2 & 0.396 \\
\hline Low & \multicolumn{2}{|c|}{7 (9.3\%) } & \multicolumn{2}{|c|}{$14(18.6 \%)$} & \multicolumn{2}{|c|}{$21(14.0 \%)$} & & \\
\hline \multicolumn{9}{|l|}{ Education } \\
\hline Primary school & \multicolumn{2}{|c|}{$11(18.4 \%)$} & \multicolumn{2}{|c|}{$5(8.4 \%)$} & \multicolumn{2}{|c|}{$16(13.4 \%)$} & & \\
\hline Middle school & \multicolumn{2}{|c|}{$5(8.3 \%)$} & \multicolumn{2}{|c|}{$3(5.0 \%)$} & \multicolumn{2}{|c|}{$8(6.7 \%)$} & 3 & 0384 \\
\hline High school & \multicolumn{2}{|c|}{$16(26.7 \%)$} & \multicolumn{2}{|c|}{$16(26.7 \%)$} & \multicolumn{2}{|c|}{$32(26.7 \%)$} & J & 0.504 \\
\hline University or vocational high school & \multicolumn{2}{|c|}{$28(46.7 \%)$} & \multicolumn{2}{|c|}{$36(60 \%)$} & \multicolumn{2}{|c|}{$64(53.3 \%)$} & & \\
\hline
\end{tabular}

*SD: standard deviation, df: Degrees of freedom

Table 2: ANOVA results for the relation of IADQ mean total scores and standard deviations with ADHD subtypes Individuals

\begin{tabular}{|c|c|c|c|c|c|c|}
\hline & $\mathbf{n}$ & Mean & SD & $\mathbf{p}$ & df & $\mathbf{F}$ \\
\hline ADHD inattentive type & 25 & 44.76 & 4.63 & $<0.001$ & 3 & 595.10 \\
\hline ADHD hyperactive-impulsive type & 10 & 57.40 & 3.13 & $<0.001$ & & \\
\hline ADHD combined type & 25 & 72.00 & 8.34 & $<0.001$ & & \\
\hline Control group & 60 & 16.60 & 5.62 & $<0.001$ & & \\
\hline
\end{tabular}

IADQ: Internet addiction diagnostic questionnaire, SD: Standard deviation, df: Degrees of freedom

ADHD, $8.3 \%$ of the hyperactive-impulsive type, and $20.8 \%$ combination type. One-way analysis of variance used to detect differences in Internet use between ADHD subtypes found that the groups with the highest Internet addiction scores were in the order ADHD combination type, predominantly hyperactive type, inattentive type, and control group (F [3, $119]=595.102, \mathrm{p}<0.001)$. Mean values for all groups are shown in Table 2.

Using chi-square test, no significant difference between the members of the control group and the ADHD group was found regarding preferred devices for Internet use $(p=0.21)$ and preferred environment for Internet use ( $\mathrm{p}=0.843)(\mathrm{p}>0.05$ in both cases). Between the ADHD subtypes, one-way analysis of variance found no difference in the preferred environment for Internet use $(p=0.742)$; however, for the preferred device to access the Internet, one significant difference was found between adolescents with inattentive type ADHD and those with hyperactive-impulsive type $(\mathrm{p}<0.001)$. According to frequency distribution analysis, participants both in the control group and in the ADHD group preferred the home as the place to use the Internet, and the devices used by control group and
ADHD group to access the Internet were computer $(\mathrm{n}=47)$ and mobile phone $(\mathrm{n}=37)$.

Correlation analysis evaluating the relation between IADQ total score and time spent on the Internet found that with increasing time, the IADQ score increased, too, so the level of addiction was higher $(r=0.68 ; p<0.001)$. Regression analysis for the relation between IADQ total score and time spent on the Internet found a statistically significant positive linear correlation $(t=10.25, \mathrm{p}<0.001)$. A significant difference was found between the control group and the ADHD group for time spent on the Internet, using one-way analysis of variance ( $\mathrm{F}[3$, $119]=56.84, \mathrm{p}<0.001$ ) (Figure 1). A statistically significant difference was found for time spent on the Internet between inattentive-type ADHD, hyperactiveimpulsive type, and combination type $(\mathrm{p}<0.001)$. Comparing the times spent on the Internet between ADHD subtypes by chi-square test, we found that the individuals in the combination type group tended to spend 6-8 hours online, persons of the hyperactiveimpulsive type 3-5 hours, and participants in the inattentive type group 0-2 hours $\left(\chi^{2}=64.951, p<0.001\right)$.

We compared control group and study group regarding the kind of use of their time spent online by 


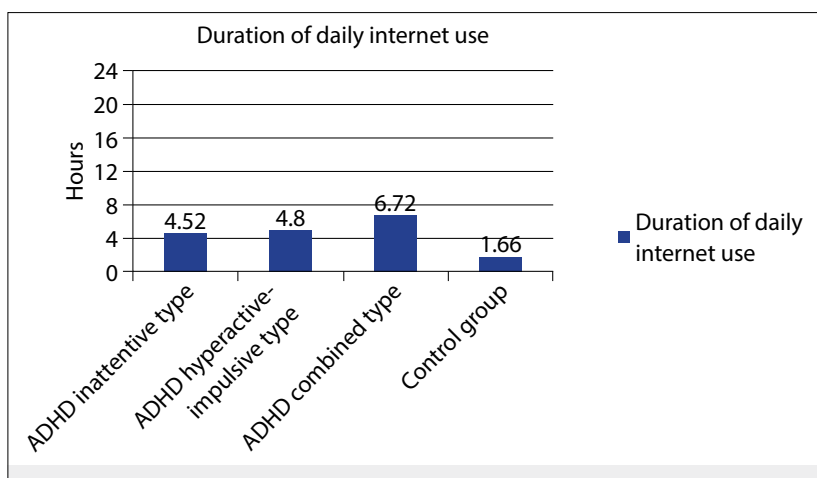

Figure 1. Distribution of mean duration of internet use by group.

chi-square test; no differences were found for watching movies and listening to music $\left(\chi^{2}=1.843, \mathrm{p}=0.398\right)$, chatting $\left(\chi^{2}=4.335, \mathrm{p}=0.228\right)$, and working on assignments $\left(\chi^{2}=0.209, p=0.648\right)$, but differences between the groups in time spent playing games $\left(\chi^{2}=30.42\right.$, $\mathrm{p}<0.001)$ and the use of social media $\left(\chi^{2}=17.191, \mathrm{p}<0.001\right)$ were significant. We used chi-square test to analyze the preferred purposes of Internet use among adolescents with ADHD, of whom $49.2 \%$ spent $0-2$ hours of their online time to play games, $35.8 \%$ spent $3-5$ hours, and $14.2 \%$ 6-8 hours for that purpose $\left(\chi^{2}=30.42, \mathrm{p}<0.001\right)$; for the use of social media, $73.3 \%$ spent $0-2$ hours and $25.8 \%$ 3-5 hours $\left(\chi^{2}=17.19, \mathrm{p}<0.001\right)$. There was no significant difference between groups regarding Internet use for assignments $\left(\chi^{2}=-209, \mathrm{df}=1\right)$, chatting $\left(\chi^{2}=4.33, \mathrm{df}=3\right)$, and films or music $\left(\chi^{2}=1.54, \mathrm{df}=2\right)(\mathrm{p}>0.05)$.

We compared control and study groups by chisquare test regarding family problems experienced due to excessive Internet use; $72.1 \%$ of adolescents in the
ADHD group ( $n=49)$ had experienced more problems in their families and were more likely to have been given Internet bans by their families, while in the control group, $27.9 \%(\mathrm{n}=19)$ had experienced family problems $\left(\chi^{2}=30.543, \mathrm{p}<0.001\right)$.

Comparing BPAQ scores between control group and ADHD group using ANOVA, the highest scores were found in the order combination-type ADHD, hyperactive-impulsive type, inattentive type, and control group. While the control group differed from the study group regarding their BPAQ scores, all children in the former group showed low aggression ( $\mathrm{F}$ $(3,119)=324.68, \mathrm{p}<0.001)$. Mean values for the groups are shown in Table 3.

Evaluating BPAQ and IADQ scores by sex, using descriptive statistical analysis, we found a mean total BPAQ score for girls of $38.63 \pm 29.77$ and a mean IADQ score of $33.05 \pm 23.67$; for boys, the mean total BPAQ score was $43.02 \pm 31.10$, the mean IADQ score $38.83 \pm 23.90$. While the difference in BPAQ and IADQ scores by sex was not significant, it came close to the threshold $(\mathrm{p}=0.58)$.

T-test was used to determine if the subdimensions of the BPAQ differed according to groups; scores for physical aggression, verbal aggression, anger, hostility, and indirect aggression were significantly different $(\mathrm{p}<0.001)$. The $\mathrm{t}$-test results showed that in adolescents diagnosed with ADHD, mean scores for physical and verbal aggression, anger, hostility, and indirect aggression were significantly higher than in the control group (Table 4). In other words, children with ADHD

Table 3: ANOVA results for BPAQ mean total scores and standard deviation Individuals

\begin{tabular}{lccccc} 
& $\mathbf{n}$ & Mean & SD & p & df \\
\hline ADHD inattentive type & 25 & 58.04 & 15.37 & $<0.001$ & 3 \\
ADHD hyperactive-impulsive type & 10 & 59.70 & 5.25 & $<0.001$ & 324.68 \\
ADHD combined type & 25 & 89.05 & 16.53 & $<0.001$ & \\
Control group & 60 & 16.11 & 4.51 & $<0.001$ & \\
\hline
\end{tabular}

BPAQ: Buss-Perry Aggression Questionnaire, SD: Standard deviation

Table 4: Results of t-test for BPAQ subdimensions

\begin{tabular}{|c|c|c|c|c|c|c|c|}
\hline & \multicolumn{2}{|c|}{ Control group $n=60$} & \multicolumn{2}{|c|}{ Study group $n=60$} & \multirow[b]{2}{*}{$\mathbf{t}$} & \multirow[b]{2}{*}{ df } & \multirow[b]{2}{*}{$\mathbf{p}$} \\
\hline & Mean & SD & Mean & SD & & & \\
\hline Physical aggression & 3.73 & 1.99 & 21.13 & 6.88 & 18.79 & 33 & $<0.001$ \\
\hline Verbal aggression & 0.76 & 1.34 & 11.48 & 4.07 & 19.33 & 33 & $<0.001$ \\
\hline Anger & 5.08 & 1.54 & 14.51 & 4.38 & 15.72 & 33 & $<0.001$ \\
\hline Hostility & 4.83 & 2.23 & 17.65 & 8.17 & 11.708 & 33 & $<0.001$ \\
\hline
\end{tabular}

BPAQ: Buss-Perry Aggression Questionnaire, SD: Standard deviation, df: Degrees of freedom 
Table 5: ANOVA results for ADHD subtypes related to BPAQ subdimensions

\begin{tabular}{|c|c|c|c|c|c|c|c|c|c|}
\hline & \multicolumn{2}{|c|}{$\begin{array}{l}\text { ADHD combined } \\
\text { type } n=20\end{array}$} & \multicolumn{2}{|c|}{$\begin{array}{l}\text { ADHD inattentive } \\
\text { type } n=24\end{array}$} & \multicolumn{2}{|c|}{$\begin{array}{l}\text { ADHD hyperactive- } \\
\text { impulsive type } n=10\end{array}$} & \multirow[b]{2}{*}{$\mathbf{F}^{*}$} & \multirow[b]{2}{*}{$\begin{array}{c}\text { Paired } \\
\text { comparison }^{a}\end{array}$} & \multirow[b]{2}{*}{$\mathbf{p}$} \\
\hline & Mean & SD & Mean & SD & Mean & SD & & & \\
\hline Physical aggression & 27.76 & 3.66 & 16.44 & 4.42 & 16.30 & 3.68 & 368.498 & Comb.>Hyp.>Inatt. & $<0.001$ \\
\hline Verbal aggression & 15.12 & 2.94 & 8.72 & 2.83 & 9.30 & 1.05 & 299.378 & Comb.>Inatt.>Hyp. & $<0.001$ \\
\hline Anger & 16.76 & 4.52 & 13 & 4.00 & 12.70 & 2.16 & 105.548 & Comb.>Hyp.>Inatt. & $<0.001$ \\
\hline Hostility & 24.40 & 7.31 & 13 & 5.13 & 12.40 & 2.91 & 116.390 & Comb.>Hyp.>Inatt. & $<0.001$ \\
\hline
\end{tabular}

BPAQ: Buss-Perry Aggression Questionnaire, Comb.: ADHD combined type, Inatt.: ADHD inattentive type; Hyp.: ADHD hyperactive-impulsive type,

SD: Standard deviation, ${ }^{\mathrm{a}} \mathrm{p}<0.05$

were found to be more likely to harm others physically by pushing, hitting, and tugging, using psychologically more hurtful words against others, sometimes sending signals that were detrimental to others not directly by in oblique ways, becoming angry more easily and feeling more hostility and vengefulness towards others.

One-way analysis of variance was used to test if BPAQ scores differed between ADHD subtypes; all BPAQ subscores for combination-type ADHD cases differed significantly from those with inattentive and hyperactivity-impulsive type ADHD (F $[3,90]=52.66$, $\mathrm{p}<0.001)$. It was found that patients with combinationtype ADHD were more prone than the other two groups to cause physical harm to other children, were more offensive verbally, got angry more easily, and if not directly, hurt their opponents indirectly. The distribution of BPAQ subdimensions according to ADHD subtypes is presented in Table 5.

Pearson correlation analysis determined a positive relation between total IADQ score and total BPAQ score $(\mathrm{r}=0.92, \mathrm{p}<0.001)$; in other words, with increasing Internet use, aggression also increased. Regression analysis examining the relation between total IADQ and total BPAQ scores confirmed a statistically significant positive linear correlation between the two scale scores $(\mathrm{t}=25.842, \mathrm{p}<0.001)$.

\section{DISCUSSION}

The results of our analyses show that in adolescents diagnosed with ADHD, aggression increases with increasing Internet use. A positive correlation between Internet use and aggression is consistent with the literature $(25,26)$.

Regarding sex, there are conflicting findings in the literature. While there are studies reporting higher Internet addiction and aggression scores for boys compared to girls (27-29), there are also studies showing no such difference. Our study is consistent with the literature, for example with research by Lam et al. (30), Bolat-Karatas (31), and Aglamaz (32) that found no significant difference between the sexes.

Yoo et al. showed a correlation between Internet addiction and ADHD and pointed out that a comorbidity of hyperactivity-impulsivity-type attention deficit represented an important risk factor for Internet addiction (10). In line with the literature, children and adolescents diagnosed with ADHD scored higher on the Internet addiction questionnaire. Some studies report that Internet addiction is seen more commonly among ADHD patients and that the presence of ADHD indicates higher addiction scores, and some say that the most common comorbidity in Internet addiction is $\operatorname{ADHD}(10,11,33)$. In our study, comparing Internet addiction by ADHD subtype, we found Internet addiction most commonly in adolescents with combination-type ADHD, which is similar to the results reported by Cao et al. (34) and Metin et al. (29). The literature frequently mentions characteristics such as increased reward sensitivity in ADHD, getting bored easily (35), a preference for quickly changing stimuli with a fast response, an orientation towards smaller short-term rather than long-term rewards, impulsivity (34) and disinhibition (36), pointing out that these desires are sufficiently satisfied by Internet use or that ADHDspecific problems with self-control increase the predisposition towards Internet addiction $(10,35)$.

Our study also obtained important information about the relation between duration of Internet use and purpose. Adolescents with ADHD spent 5.5 \pm 2.5 hours online, adding up to 38.5 hours of Internet use per week, which is consistent with the study by Young who found that the Internet addiction group spent an average of 39 hours per week on the Internet (37).

In our study, we found that the devices most commonly used for Internet access were computer and mobile phone and the most common environment to use the Internet was the home, which corresponds to the results of a study by Batigun and Kilic (38). Similar 
to a study by Ko et al., (39) we found that a high proportion of excessive Internet users connected from home, where the accessibility of the Internet constituted a risk factor for addiction. Due to the intensive use of media like the Internet, children and adolescents experience significant problems with their families (29). Similarly, our study found that adolescents with intensive Internet use encountered more problems with their families, including a more frequent ban on Internet use. For parents, being aware of the risk of excessive Internet use will be the most decisive factor for preventing addiction (40).

Deficits of behavioral inhibition in ADHD, a neurodevelopmental disorder, have been suggested as a cause for social and cognitive problems and aggression (41). It has been reported that aggression co-occurs with expressive disorders such as ADHD, conduct disorder, and oppositional defiant disorder (42), and particularly in the hyperactive-impulsive and combination types of ADHD, anger and emotional outbursts are seen more frequently (16). Similar to these results, our study found aggression scores in combination-type ADHD to be elevated. Our results are supported by a study carried out by Demirci and Oztop who determined that BPAQ scores in the ADHD group were significantly higher than in the control group (43). It has been reported that males diagnosed with ADHD showed a higher inclination towards aggression. This finding is consistent with the results of studies by Sahin (25) and Ozturk et al. (44).

To our knowledge, no study has been done in Turkey to assess the correlations between ADHD subtypes and BPAQ subdimensions. In our study, there was a significant difference between ADHD subtypes regarding BPAQ subdimensions physical aggression, verbal aggression, anger, and indirect aggression; adolescents with combination-type ADHD scored higher in these subdimensions, while there was no difference in the hostility subdimension.

Finally, Internet addiction and aggression rate in adolescents with ADHD were higher than in the control group. In other words, adolescents diagnosed with ADHD were found to use the Internet more and in a more uncontrolled way and were more aggressive and angry towards their environment. Increased Internet addiction and aggression were especially found in adolescents with combination-type ADHD.

When assessing the final results of the study, we need to consider certain limitations, the most important one being the low number of participants. Secondly, information on aggression and addiction used as a foundation for the study was obtained by self-report instruments. As ADHD is one of the conditions most closely associated with aggression and Internet addiction in adolescents, it is necessary to assess aggression, Internet addiction, and related risk factors in ADHD cases in a detailed manner and to take preventive measures early on. Our results provide some information about risk factors to be addressed when dealing with Internet addiction (such as time spent online or environment of Internet use). Therefore, when excessive Internet use and aggressive behavior are found together during the clinical assessment of adolescents with ADHD, given the positive correlation between excessive Internet use and aggression and considering the ADHD-specific self-control problems, coordinated treatment of aggressive behavior shown in connection with excessive Internet use could be considered more beneficial in the light of our results.

Finally, we can say that these results are helpful in the treatment of aggressive behavior in adolescents with ADHD from the perspective of preventive measures relating to Internet addiction. For future studies, it can be recommended to analyze the relation between Internet addiction and aggression in the presence of psychiatric disorders other than ADHD.

\begin{tabular}{|c|c|c|}
\hline \multicolumn{2}{|c|}{ Contribution Categories } & \multirow{2}{*}{$\begin{array}{l}\text { Author Initials } \\
\text { M.I. }\end{array}$} \\
\hline \multirow{3}{*}{ Category 1} & Concept/Design & \\
\hline & Data acquisition & M.I., S.B.I. \\
\hline & Data analysis/Interpretation & S.B.I. \\
\hline \multirow{2}{*}{ Category 2} & Drafting manuscript & E.S.E. \\
\hline & Critical revision of manuscript & S.B.I., M.I., E.S.E. \\
\hline Category 3 & Final approval and accountability & S.B.I., M.I., E.S.E. \\
\hline \multirow{2}{*}{ Other } & Technical or material support & E.S.E \\
\hline & Supervision & E.S.E \\
\hline
\end{tabular}

Acknowledgements: We are very grateful to Spec. Dr. Ulku Akyol Ardic for her support during data collection.

Ethics Committee Approval: The study was approved by the Ethics Committee of the Hasan Kalyoncu University.

Informed Consent: Adolescents and their families were informed about the study, and a verbal consent form was received from those volunteering to participate.

Peer-review: Externally peer-reviewed.

Conflict of Interest: The authors declared no conflict of interest.

Financial Disclosure: None declared.

\section{REFERENCES}

1. Akay AP, Ercan ES. Child and Adolescent Mental Health and Diseases. Ankara: Turkiye Cocuk ve Genc Psikiyatri Dernegi Yayinlari, 2016, 2. (Turkish) 
2. American Psychiatric Association. Diagnostic and Statistical Manual of Mental Disorders Fifth ed. (DSM-5), Washington DC: American Psychiatric Publ., 2013. [CrossRef]

3. Young KS. Internet addiction: a new clinical phenomenon and its consequences. Am Behav Sci 2004; 48:402-415. [CrossRef]

4. Yau YHC, Yip SW, Potenza MN. Understanding "behavioral addictions": insights from research: In Ries RK, Fiellin DA, Miller SC, Saitz R (editors). The ASAM Principles of Addiction Medicine; Fifth ed. Philadelphia : Wolters Kluwer Health, 2014, 55-82.

5. Durkee T, Kaess M, Carli V, Parzer P, Wasserman C, Floderus B, Apter A, Balazs J, Barzilay S, Bobes J, Brunner R, Corcoran P, Cosman D, Cotter P, Despalins R, Graber N, Guillemin F, Haring C, Kahn JP, Mandelli L, Marusic D, Meszaros G, Musa GJ, Postuvan V, Resch F, Saiz PA, Sisask M, Varnik A, Sarchiapone M, Hoven CW, Wasserman D. Prevalence of pathological internet use among adolescents in Europe: demographic and social factors. Addiction 2012; 107:2210-2222. [CrossRef]

6. Gunuc S, Kayri M. The profile of internet dependency in Turkey and development of Internet addiction scale: study of validity \& reliability. Hacettepe University Journal of Education 2010; 39:220-232. (Turkish)

7. Comert IT, Ogel K. Prevalence factors for Internet and computer addiction in [sic] Istanbul sample. Turkiye Klinikleri Journal of Forensic Medicine and Forensic Sciences 2009; 6:916. (Turkish)

8. Tsitsika A, Critselis E, Louizou A, Janikian M, Freskou A, Marangou E, Kormas G, Kafetzis DA. Determinants of Internet addiction among adolescent: a case-control study. ScientificWorldJournal 2011; 11:866-874. [CrossRef]

9. Spada MM. An overview of problematic internet use. Addict Behav 2014; 39:3-6. [CrossRef]

10. Yoo HJ, Cho SC, Ha J, Yune SK, Kim SJ, Hwang J, Chung A, Sung YH, Lyoo IK. Attention deficit hyperactivity symptoms and Internet addiction. Psychiatry Clin Neurosci 2004; 58:487-494.

11. Yen JY, Ko CH, Yen CF, Wu HY, Yang MJ. The comorbid psychiatric symptoms of Internet addiction: attention deficit and hyperactivity disorder (ADHD), depression, social phobia, and hostility. J Adolesc Health 2007; 41:93-98. [CrossRef]

12. Ko CH, Liu TL, Wang PW, Chen CS, Yen CF, Yen JY. The exacerbation of depression, hostility and social anxiety in the course of Internet addiction among adolescents: a prospective study. Compr Psychiatry 2014; 55:1377-1384. [CrossRef]

13. Retz $\mathrm{W}$, Rosler $\mathrm{M}$. The relation of $\mathrm{ADHD}$ and violent aggression: what can we learn from epidemiological and genetic studies? Int J Law Psychiatry 2009; 32:235-243. [CrossRef]

14. Barkley RA, Murphy KR, Fischer M. ADHD in Adults: What the Science Says. New York: Guilford Press, 2008.

15. Lee BW, Stapinski LA. Seeking safety on the internet: relationship between social anxiety and problematic internet use. J Anxiety Disord 2012; 26:197-205. [CrossRef]

16. Bagwell CL, Molina BS, Pelham WE Jr, Hoza B. Attentiondeficit hyperactivity disorder and problems in peer relations: predictions from childhood to adolescence. J Am Acad Child Adolesc Psychiatry 2001; 40:1285-1292. [CrossRef]
17. Yen JY, Ko CH, Yen CF, Chen SH, Chung WL, Chen CC. Psychiatric symptoms in adolescents with Internet addiction: comparison with substance use. Psychiatry Clin Neurosci 2008; 62:9-16. [CrossRef]

18. Ko CH, Yen JY, Liu SC, Huang CF, Yen CF. The associations between aggressive behaviors and internet addiction and online activities in adolescents. J Adolesc Health 2009; 44:598-605.

19. Kaufman J, Birmaher B, Brent D, Rao U, Flynn C, Moreci P, Williamson D, Ryan N. Schedule for Affective Disorders and Schizophrenia for School-Age Children-Present and Lifetime Version (K-SADS-PL): initial reliability and validity data. J Am Acad Child Adolesc Psychiatry. 1997;36:980-988. [CrossRef]

20. Gokler B, Unal F, Pehlivanturk B, Kultur EC, Akdemir D, Taner Y. Reliability and validity of Schedule for Affective Disorders and Schizophrenia for School Age Children - present and lifetime version - Turkish version (K-SADS-PL-T). Cocuk ve Genclik Ruh Sagligi Dergisi 2004; 11:109-116. (Turkish)

21. Young KS. Internet addiction: symptoms, evaluation and treatment: In VandeCreek L, Jackson T (editors). Innovations in Clinical Practice: A Source Book. Sarasota, FL. Professional Resource Press, 1998; 16:19-31.

22. Bayraktar F. The Role of Internet Use in Adolescent Development. Unpublished M.A. thesis, Ege University, Social Sciences Institute, Izmir, 2001. (Turkish)

23. Buss AH, Warren WL. Aggression Questionnaire: Manual. Los Angeles: Western Psychological Services, 2002.

24. Can S. Validity and Reliability Study for the Aggression Questionnaire in a Turkish population. Unpublished Specialization Thesis, Istanbul Gulhane Military Medicine Academy, Directorate for Mental Health and Diseases, 2002.

25. Sahin M. The internet addiction and aggression among university students. Dusunen Adam The Journal of Psychiatry and Neurological Sciences 2014; 27:43-52. [CrossRef]

26. Madran $\mathrm{AD}$, Cakilci EF. The relationship between aggression and online video game addiction: a study on massively multiplayer online video game players. Anadolu Psikiyatri Derg 2014; 15:99107. (Turkish) [CrossRef]

27. Gunuc S. Development of an Internet Addiction Scale and Study of the Relations between Certain Demographic Variables and Internet Dependency. M.A. Thesis, Yuzuncu Yil University, Van, 2009.

28. Morahan-Martin J. Internet abuse: Addiction? Disorder? Symptom? Alternative Explanations? Soc Sci Comput Rev 2005; 23:39-48. [CrossRef]

29. Metin O, Saracli O, Atasoy N, Senormanci O, Cakir-Kardes V, Acikgoz HO, Demirci E, Ayan UB, Atik L, Tahiroglu AY. Association of internet addiction in high school students with ADHD and tobacco/alcohol use. Dusunen Adam The Journal of Psychiatry and Neurological Sciences 2015; 28:204-212. [CrossRef]

30. Lam LT, Peng ZW, Mai JC, Jing J. Factors associated with internet addiction among adolescents. Cyberpsychol Behav 2009; 12:551555. [CrossRef]

31. Bolat-Karatas Z. A Study of the Relationship Between Parental Aggression and High School Student Aggression. Unpublished M.A. Thesis. Cukurova University Social Sciences Institute. Adana, 2002. 
32. Aglamaz T. Study of High School Student Aggression Scores Related to Distress Disclosure, Type of School, Sex, Class Level, Parents' Level of Education, and Monthly Family Income. Unpublished M.A. Thesis. 19 May University Social Sciences Institute. Samsun, 2006.

33. Tahiroglu AY, Celik GG, Fettahoglu C, Yildirim V, Toros F, Avci A, Ozatalay E, Uzel M. Problematic internet use in the psychiatric sample compared [sic] community sample. Noro Psikiyatr Ars 2010; 47:241-246.

34. Cao F, Su L, Liu T, Gao X. The relationship between impulsivity and Internet addiction in a sample of Chinese adolescents. Eur Psychiatry 2007; 22:466-471. [CrossRef]

35. Castellanos FX, Tannock R. Neuroscience of attention-deficit/ hyperactivity disorder: the search for endophenotypes. Nat Rev Neurosci 2002; 3:617-628. [CrossRef]

36. Sun DL, Chen ZJ, Ma N, Zhang XC, Fu XM, Zhang DR. Decision-making and prepotent response inhibition functions in excessive internet users. CNS Spectr 2009; 14:75-81. [CrossRef]

37. Young KS. Internet addiction: the emergence of a new clinical disorder. Cyberpsychol Behav 1998; 1:237-244. [CrossRef]

38. Batigun DA, Kilic N. Relations Between Internet addiction and personal characteristics, social support, psychological symptoms, and certain sociodemographic variables. Turk Psikiyatri Derg 2011; 26:1-10. (Turkish)
39. Ko CH, Yen JY, Yen CF, Lin HC, Yang MJ. Factors predictive for incidence and remission of internet addiction in young adolescents: a prospective study. Cyberpsychol Behav 2007; 10:545-551.

40. Barkin S, Ip E, Richardson I, Klinepeter S, Finch S, Krcmar M. Parental media mediation styles for children aged 2 to 11 years. Arch Pediatr Adolesc Med 2006; 160:395-401. [CrossRef]

41. Barkley RA, Smith KM, Fischer M, Navia B. An examination of the behavioral and neuropsychological correlates of three ADHD candidate gene polymorphisms (DRD4 7+, DBH TaqI A2, and DAT1 40 bp VNTR) in hyperactive and normal children followed to adulthood. Am J Med Genet B Neuropsychiatr Genet 2006; 141B:487-498. [CrossRef]

42. Weiss M, Weiss G. Attention Deficit Hyperactivity Disorder: In Lewis, $M$ (editor). Child and Adolescent Psychiatry: A Comprehensive Textbook. Third ed., Philadelphia: Lippincott Williams and Wilkins, 2002, 645-670.

43. Demirci EO, Oztop DB. The relation between aggression, empathy and 2D:4D ratio in male children and adolescents with attention-deficit and hyperactivity disorder. Yeni Symposium 2015; 53:2-9. (Turkish) [CrossRef]

44. Ozturk Y, Ozyurt G, Tufan AE, Pekcanlar AA. Emotion dysregulation in attention deficit and hyperactivity disorder and its treatment. Current Approaches in Psychiatry 2018; 10:198211. (Turkish) 